\title{
İki Farklı Polimerin Sondaj Çamuru Özellikleri Üzerine Etkileri
}

\author{
İlker Acar ${ }^{1 *}$, Ercan Doğan ${ }^{2}$, Furkan Urhan ${ }^{3}$, Ahmet Ömür $\mathrm{Ak}^{4}$ \\ $1^{*}$ Atatürk Üniversitesi, Oltu Yer Bilimleri Fakültesi, Petrol ve Doğal Gaz Mühendisliği Bölümü, Oltu, Erzurum, Türkiye (ORCID: 0000-0001-9439-1580), \\ ilker.acar@atauni.edu.tr \\ ${ }^{2}$ Atatürk Üniversitesi, Oltu Yer Bilimleri Fakültesi, Petrol ve Doğal Gaz Mühendisliği Bölümü, Oltu, Erzurum, Türkiye (ORCID: 0000-0001-7384-5838), \\ ercan.dogan@atauni.edu.tr \\ ${ }^{3}$ Atatürk Üniversitesi, Oltu Yer Bilimleri Fakültesi, Petrol ve Doğal Gaz Mühendisliği Bölümü, Oltu, Erzurum, Türkiye (ORCID: 0000-0003-2510-129X), \\ furkanurhan41@hotmail.com \\ ${ }^{4}$ Atatürk Üniversitesi, Oltu Yer Bilimleri Fakültesi, Petrol ve Doğal Gaz Mühendisliği Bölümü, Oltu, Erzurum, Türkiye (ORCID: 0000-0003-3601-4407), \\ ak_omur@hotmail.com
}

(İlk Geliş Tarihi 6 Temmuz 2020 ve Kabul Tarihi 27 Ekim 2020)

(DOI: $10.31590 /$ ejosat.765132)

ATIF/REFERENCE: Acar, İ., Doğan, E., Urhan, F. \& Ak, A.Ö. (2020). İki Farklı Polimerin Sondaj Çamuru Özellikleri Üzerine Etkileri. Avrupa Bilim ve Teknoloji Dergisi, (20), 479-484.

\section{$\ddot{O} z$}

Bu çalışmada, iki farklı anyonik polimer katkısının bentonitli bir sondaj çamurunun verimi, su kaybı (filtrasyon) ve reolojik özellikleri üzerine etkileri incelenmiştir. Bu kapsamda, öncelikle katkısız çamur özellikleri ağırlıkça dört farklı bentonit yüzdesi (\%4, 6, 8 ve 10) için belirlenmiştir. Sonrasında \%4 ve 6 bentonit içerikleri için, sırasıyla polianyonik selülozik (PAC) ve poliakrilamid yapılarına sahip, QUIK-TROL GOLD (QTG) ve POLY-VIS (PV) polimerlerinin etkisi 0,5-3,0 kg/m $\mathrm{m}^{3}$ dozaj aralığında incelenmiştir. Elde edilen çamurların özellikleri API Standardı 13A'ya göre değerlendirilmiştir. Katkısız çamur testleri, 17,69 $\mathrm{m}^{3} /$ ton olarak hesaplanan çamur veriminin, gerekli alt limit olan $15,8 \mathrm{~m}^{3} /$ ton değerini karşıladığını göstermiştir. 15 cp'lik görünür viskozite alt sınırı, \%6 ve üzerindeki bentonit içeriklerinde sağlanmıştır. Akma noktası/plastik viskozite oranı için sondaj kalite bentonitten beklenen üst sınır değer olan 3 , yalnızca \%4'lük çamur için karşılanırken, OCMA kalite için ise \%4 ve 6'lık çamurlar üst sınır değer olan 6'yı aşmayan sonuçlar sergilemiştir. Su kaybı değerleri, test edilen tüm katı içeriklerinde OCMA üst limiti olan 16 mL'yi geçmezken, yalnızca \%4'lük çamur için elde edilen 15,63 mL'lik kayıp sondaj kalite üst sınırını azda olsa aşmıştır. Genel olarak, \%6'lık çamur OCMA standardını karşılamasına rağmen, elde edilen düşük plastik viskozite ve yüksek akma noktası/plastik viskozite oranı, bentonitin katkısız olarak kullanılamayacağını göstermiştir. Katkılı çamur testlerine göre, \%4'lük çamur için, sondaj kalite bentonitten beklenen tüm spesifikasyonların sağlandığı minimum polimer dozajları, QTG ve PV'nin her ikisi için de 1,5 kg/m² olarak belirlenmiştir. Bu dozaj değeri için, QTG PV'den \%7,14 daha düşük su kaybı değeri sağlarken, PV ise QTG'ye oranla görünür viskozite ve çamur verimi değerlerinde sırasıyla \%37,04 ve 37,98 artışa neden olmuştur. \%6'lık çamurda, her iki polimerin test edilen tüm dozajları için beklendiği gibi çok düşük su kaybı değerleri elde edilmiştir. Ek olarak, aynı bentonit içeriği için QTG'nin $1 \mathrm{~kg} / \mathrm{m}^{3}$ dozajında elde edilen $21,5 \mathrm{cp}$ görünür viskozite, $11 \mathrm{cp}$ plastik viskozite, $21 \mathrm{lbf} / 100 \mathrm{ft}^{2}$ akma noktası ve 1,91 akma noktası/plastik viskozite oranı, sondaj için belirlenen tüm standart değerlerin karşılandığını göstermiştir. Diğer yandan, PV'nin $0,5 \mathrm{~kg} / \mathrm{m}^{3}$ dozajında dahi elde edilen $51 \mathrm{lbf} / 100 \mathrm{ft}{ }^{2}$ akma noktası ve özellikle 5,67 akma noktası/plastik viskozite oranı, bu katı içeriğinde kullanımının mümkün olmadığını işaret etmektedir. Genel sonuçlar, \%4'lük çamurun 1,5 kg/m³ QTG ve PV dozajları için sondaj kalite bir bentonitten beklenen tüm standart değerleri karşıladığını göstermiştir. Spesifik olarak, çok düşük su kaybı değerlerine ulaşabilmek için QTG, yüksek viskozite ve çamur verimi elde edebilmek için ise PV kullanılmalıdır.

Anahtar Kelimeler: Sondaj çamuru, Bentonit, Polimer, Çamur verimi, Su kaybı, Reolojik özellikler.

\section{The Effects of Two Different Polymers on the Drilling Mud Properties}

\begin{abstract}
In this study, the effects of two different anionic polymer additives on the yield, water loss (filtration) and rheological properties of a bentonite-based drilling mud were investigated. Within this scope, the properties of polymer-free mud were first determined using four different bentonite percentages of 4, 6, 8 and $10 \%$ by weight. For the bentonite contents of 4 and 6\%, the effects of QUIK-TROL GOLD (QTG) and POLY-VIS (PV) polymers with the respective polyanionic cellulosic (PAC) and polyacrylamide structures were then
\end{abstract}

*Sorumlu Yazar: ilker.acar@atauni.edu.tr 
examined for the dosages in the range of $0.5-3.0 \mathrm{~kg} / \mathrm{m}^{3}$. The properties of the muds obtained were evaluated with respect to API Standard 13A. The polymer-free mud tests showed that the mud yield calculated as $17.69 \mathrm{~m}^{3} /$ ton meets the required lower limit of $15.8 \mathrm{~m}^{3} /$ ton. For the apparent viscosity, the lower limit value of $15 \mathrm{cp}$ is provided with bentonite contents of $6 \%$ and above. While the upper limit value of 3 expected from the drilling quality bentonite in terms of the ratio of yield point to plastic viscosity was met only for the $4 \%$ mud, the muds prepared with both 4 and $6 \%$ bentonite exhibited the values which did not exceed the upper limit of 6 for the OCMA quality. While the obtained water loss values stay within the OCMA upper limit of $16 \mathrm{~mL}$ for all of the solid contents tested, the loss of $15.63 \mathrm{~mL}$ obtained for $4 \%$ mud only exceeded the upper limit of drilling quality in low amount. In general, although the $6 \%$ mud meets the OCMA standard, the resulting low plastic viscosity and high ratio of yield point to plastic viscosity showed that bentonite sample cannot be used without additives. According to the mud tests with polymer additives, for $4 \%$ bentonite, the minimum polymer dosages, which all of the specifications expected from drilling quality bentonite were met, was determined as $1.5 \mathrm{~kg} / \mathrm{m}^{3}$ for both QTG and PV. QTG provides 7.14\% lower water loss value than PV for this dosage, while PV exhibited 37.04 and $37.98 \%$ increases in the respective apparent viscosity and mud yield values compared to QTG. For 6\% bentonite, very low water loss values were obtained for all of the tested dosages of both polymers as expected. In addition, for the same bentonite content, the obtained apparent viscosity of $21.5 \mathrm{cp}$, plastic viscosity of $11 \mathrm{cp}$, yield point of $21 \mathrm{lbf} / 100 \mathrm{ft}^{2}$ and ratio of yield point to plastic viscosity of $1.91 \mathrm{for}$ QTG dosage of $1 \mathrm{~kg} / \mathrm{m}^{3}$ showed that all of the standart values for the drilling quality were met. On the other hand, the obtained $51 \mathrm{lbf} / 100 \mathrm{ft}^{2} \mathrm{yield} \mathrm{point} \mathrm{and}$ especially 5.67 yield point to plastic viscosity ratio values at even $0,5 \mathrm{~kg} / \mathrm{m}^{3} \mathrm{PV}$ dosage point out that it is not possible to use PV with this solid content. Overall results have suggested that $4 \%$ mud meets the all standard values expected from a drilling quality bentonite for $1.5 \mathrm{~kg} / \mathrm{m}^{3}$ dosages of QTG and PV. Specifically, QTG should be used to achieve very low water loss values while PV should be used to obtain high viscosity and mud yield.

Keywords: Drilling mud, Bentonite, Polymer, Mud yield, Water loss, Rheological properties.

\section{Giriş}

Sondaj, yeraltında bulunan petrol, doğalgaz ve jeotermal enerji gibi kaynakların aranması ve üretimini sağlayan son derece önemli bir prosestir (Balkaya et al., 2019). Temelde su ve şişme özelliği bulunan kilden meydana gelen sondaj çamuru, günümüzde tek kullanılan yöntem olan döner sondajın ayrılmaz bir parçasıdır ve sondaj esnasında birçok hayati işleve sahiptir. Kırıntıları kuyunun dışına çıkarmak, matkabı soğutmak, kuyudaki çöküntüleri önlemek, formasyon basıncını dengelemek, sondaj dizisini ve kuyunun çeperlerini yağlayarak hareketlerini kolaylaştırmak, sondaj durdurulduğu süre boyunca kırıntı ve kum taneciklerini askıda tutarak kuyu dibinde birikmesini önlemek ve sondaj dizisi ile muhafaza borularının ağırlıklarını hafifletmek sondaj çamurunun başlıca görevleri arasındadır (Asker, Özkan, \& Özkan, 2019; Karg1, 2015; Okon, Udoh, \& Bassey, 2014; Onat, 1971).

Yüksek çamur verimi (hacimce yüksek oranda şişmesi) ve uygun reolojik özellikleri nedeniyle bentonitler, sondaj sektöründe oldukça yaygın bir şekilde kullanılmaktadır. Ancak bentonitin bu sektörde efektif bir şekilde kullanılabilmesi için belirli spesifikasyonlara sahip olması gerekmektedir. Diğer bir deyişle, yoğunluk, viskozite, verim ve su kaybı gibi sondaj çamuru özelliklerinin, standartlarla belirlenmiş olan sınır değerleri karşılaması beklenmektedir (Çinku, 2008). Örnek olarak, sondaj çamurunun viskozitesi arttığında taşınan kırıntı miktarı artarken çamur pompasının verimi düşmektedir. Çamurun su kaybının fazla olması durumunda ise formasyona geçen su, kayacın hacmini büyütür, kek kalınlaşması sonucu kuyu çapı da daralır. $\mathrm{Bu}$ durum sondajın zorlaşmasına ve hatta takım sıkışmasına bile neden olabilir (Avc1, 2018). Uygun çamur özelliklerinin elde edilebilmesi için çoğu zaman bentonitin tek başına kullanımı yeterli olmamaktadır. Bilhassa verim, filtrasyon kaybı ve reolojik özelliklerin optimize edilebilmesi için çeşitli kimyasal katkıların kullanılması gerekmektedir (Asker et al., 2019).

Sondaj kimyasalları, sondaj çamurunun hazırlanması, kontrolü ve ıslahı için kullanılırlar. Sondaj çamurunda kullanılan başlıca katkı malzemeleri, ağırlaştırıcılar (barit, hematit, kalsiyum karbonat), tuzlar $\left(\mathrm{NaCl}, \mathrm{KCl}, \mathrm{CaCl}_{2}\right)$, polimerler, $\mathrm{pH}$ düzenleyiciler (pH'1 arttırmak için genellikle kostik soda, düşürmek için ise sitrik asit), çeşitli türdeki kirlilikler için ıslah kimyasalları (sodyum bikarbonat, soda külü ve kireç) ve kaçak önleyicilerdir (LCM). Esasen filtrasyon, viskozite ve jel mukavemeti özelliklerini kontrol etmek için kullanılan polimerler temelde viskozite yapıc1, inceltici ve sıv1 kayb1 kontrolü sağlayanlar olarak üçe ayrılır. Bu amaçlar için sektörde yaygın olarak nişasta, zantam sakızı (XCD), yüksek ve düşük viskoziteli karboksimetil selüloz (CMC-HV ve CMC-LV), polianyonik selüloz (PAC), kromsuz lignosülfonat (CFL), sodyum asit payrofosfat (SAPP) ve kısmen hidrolize olmuş poliakrilamit (PHPA) benzeri polimerler kullanılır (Balkaya et al., 2019; Erdoğan, Kök, \& Tanrıverdi, 2017).

Bu çalışmada, sırasıyla polianyonik selüloz (PAC) ve kısmen hidrolize olmuş poliakrilamit (PHPA) yapılarına sahip QUIKTROL GOLD (QTG) ve POLY-VIS (PV) polimerlerinin bentonitli bir sondaj çamurunun verimi, filtrasyon ve reolojik özellikleri üzerine etkileri incelenmiştir. Bu kapsamda, öncelikle ağırlıkça $\% 4,6,8$ ve 10 bentonit içeren çamur özellikleri belirlenmiş ve sonrasında $\% 4$ ve 6 bentonit içerikleri için, QTG ve PV'nin etkisi $0,5-3,0 \mathrm{~kg}$ polimer $/ \mathrm{m}^{3}$ çamur aralığında ilgili API standardı uyarınca incelenmiştir.

\section{Materyal ve Metot}

\subsection{Malzeme}

Deneylerde kullanılan bentonit numunesi, Çanbensan A.Ş.'nin S-1 adlı ürünü olan sarı renkli sondaj bentonitidir. Firma, Türkiye'nin Çankırı bölgesinden çıkardığı ham bentonite öğütme esnasında kütlece \%1 oranında soda külü $\left(\mathrm{Na}_{2} \mathrm{CO}_{3}\right)$ ilave edip uygun boyuta getirerek OCMA kalite $\mathrm{S}-1$ ürününü elde etmektedir. QTG ve PV polimer katkıları, Kayen Sondaj firmasından temin edilmiştir. Kırık beyaz renge sahip ve granüler toz halde bulunan QTG, su ve sondaj çamuru içerisinde hızlı ve yüksek çözünürlüğe sahip PAC yapısında bir polimerdir. Sondaj çamurunda üst düzeyde su kaybı (filtrasyon) kontrolü özelliği ile karakterize edilir. Parlak beyaz renkli granüler PV ise $\% 90$ saflıkta PHPA yapısında olup, kil ve şeyl gibi suya hassas tabakaları dengelemek ve düşük katı oranlı çamurların viskozitesini arttırmak amacıyla kullanılır. Gerçekleştirilen tüm deneyler boyunca saf su kullanılmıştır. 


\subsection{Metot}

\subsubsection{Bentonit Karakterizasyonu}

Kullanılan bentonit numunesinin kimyasal kompozisyonu X1şını floresans (XRF) metodu ile belirlenmiştir. Mineralojik analiz, PANalytical Empyrean X-ışını kırınım (XRD) cihazı vasıtasıyla $45 \mathrm{kV}$ ve $40 \mathrm{~mA}$ koşullarında, $10-80^{\circ}$ 2Teta aralığında ve $\mathrm{Cu}-\mathrm{K} \alpha$ radyasyonu $(\lambda=1.54051 \AA)$ kullanılarak gerçekleştirilmiştir. Mikroyapısal karakterizasyon ise yüksek çözünürlüklü Zeiss Sigma 300 taramalı elektron mikroskobu (SEM) yardımıyla belirlenmiştir.

\subsection{2. Çamur Hazırlama}

Deneyler, polimer katkısız ve katkılı olarak iki aşamada gerçekleştirilmiştir. Öncelikle, polimer katkısız çamurlar ağırlıkça $\% 4,6,8$ ve 10 bentonit kullanılarak hazırlanmış ve çamur verimi, su kaybı (filtrasyon) ve reolojik özellikler yönünden test edilmiştir. Sonrasında, \%4 ve 6 bentonit içeren çamurlara QTG ve PV'nin altı farklı dozaj1 $(0,5,1,0,1,5,2,0,2,5$ ve $3,0 \mathrm{~kg}$ polimer $/ \mathrm{m}^{3}$ çamur) ilave edilerek bahsi geçen çamur özelliklerindeki değişimler incelenmiştir. Çamurlar, $350 \mathrm{ml}$ saf su eklenip Hamilton Beach çoklu mekanik karıştırıcıya yerleştirilen kaplara uygun miktardaki bentonit numunelerinin yavaşça ilave edilip 20 dakika boyunca karıştırılması ile hazırlanmıştır. Katkılı çamurlar için gerekli polimer miktarları ilave edilerek 10 dakika daha karıştırılmıştır. Hazırlanan karışımlar, ortam sıcaklığında ve hava almayacak şekilde Amerikan Petrol Enstitüsü (API) standartlarına göre bentonit çamurları için belirlenen 16 saat süresince bekletilmiştir. Çamur testleri, bekleme süresini takiben numunelerin 5 dakika karıştırılmasından sonra gerçekleştirilmiştir. Deneylerde kullanılan bentonit miktarları aşağıdaki bağıntı yardımıyla hesaplanmıştır (Yenipazar, 2000).

$$
x(g)=\frac{350 x \text { Ağırlıkça } \%}{1-\text { Ağırlıkça } \%}
$$

\subsection{3. Çamur Testleri}

Çamur yoğunlukları, ilgili API standardı uyarınca Fann 140 Çamur Terazisi kullanılarak belirlenmiştir. Görünür viskozite $\left(\mu_{\mathrm{a}}\right)$, plastik viskozite $\left(\mu_{\mathrm{p}}\right)$ ve akma noktası $\left(\tau_{\mathrm{y}}\right)$ gibi reolojik özellikler, Fann 280 Döner Viskozimetre ile 300 ve 600 devir/dakika değerlerinde gerçekleştirilen viskozite ölçümlerinden $\left(\theta_{300}\right.$ ve $\left.\theta_{600}\right)$ aşağıdaki eşitlikler yardımıyla hesaplanmıştır (Özkan \& Kaplan, 2019).

$$
\begin{aligned}
& \mu_{a}(c p)=\frac{\theta_{600}}{2} \\
& \mu_{P}(c p)=\theta_{600}-\theta_{300} \\
& \tau_{y}\left(\frac{l b f}{100 f t^{2}}\right)=\theta_{300}-\mu_{p}
\end{aligned}
$$

Çamur verimi, kullanılan kilin bir tonunun $15 \mathrm{cp}$ görünür viskoziteli çamurdan kaç metreküp üretilebileceğinin ölçüsü olarak ifade edilmektedir. Bunun için kütlece bentonit yüzdelerine karşılık elde edilen görünür viskozite değerleri grafik edilmiş ve 15 cp'a karşılık gelen değerler grafik üzerinden okunarak çamur verimi ( $\mathrm{m}^{3} /$ ton) hesaplanmıştır. Su kaybı, API standartlarına göre $100 \pm 5$ psi basınç altında $45 \mathrm{~cm}^{2}$ alandan 30 dak boyunca akan filtrasyon miktarı olarak tanımlanmıştır. Su kaybı testleri, ortam sıcaklığında Fann Yarım Alan Filtre Press kullanılarak gerçekleştirilmiştir. Testlerde, süzme işlemi için Whatman No. 50 filtre kağıtları ve basınç kaynağı olarak $\mathrm{CO}_{2}$ gazı içeren $100 \pm 5$ psi'lık tüpler kullanılmıştır. Dereceli silindirde 30 dak sonunda toplanan süzüntü hacmi, yarım alan filtre press kullanıldığından 2 ile çarpılmış ve bulunan değer çamur numunesinin su (filtrasyon) kaybı olarak kabul edilmiştir.

\section{Araştırma Sonuçları ve Tartıșma}

\subsection{Karakterizasyon Sonuçları}

Deneylerde kullanılan bentonitin kimyasal içeriği Tablo 1'de gösterilmektedir. Bentonit numunesi, beklendiği şekilde temelde bir alümina-silikat çerçeveye ve bunun içerisinde sodyum ve kalsiyum gibi değişebilir katyonlara sahiptir (Huang et al., 2016).

Tablo 1. Bentonit Numunesinin Kimyasal Kompozisyonu

\begin{tabular}{l|c}
\hline Oksit İçeriği (\%) & Bentonit Numunesi \\
\hline $\mathrm{SiO}_{2}$ & 66,01 \\
\hline $\mathrm{Al}_{2} \mathrm{O}_{3}$ & 17,00 \\
\hline $\mathrm{Fe}_{2} \mathrm{O}_{3}$ & 3,58 \\
\hline $\mathrm{CaO}$ & 1,09 \\
\hline $\mathrm{MgO}$ & 2,28 \\
\hline $\mathrm{K}_{2} \mathrm{O}$ & 1,30 \\
\hline $\mathrm{Na}_{2} \mathrm{O}$ & 2,32 \\
\hline
\end{tabular}

Şekil 1 bentonit numunesi içerisindeki kristal fazları göstermektedir. Şekil 1'den görüldüğü üzere, montmorillonit $\left(\mathrm{Na}_{0,2}, \mathrm{Ca}_{0,1}, \mathrm{Al}_{2} \mathrm{Si}_{4} \mathrm{O}_{10}(\mathrm{OH})_{2}\left(\mathrm{H}_{2} \mathrm{O}\right)_{10}\right)$, kuvars $\left(\mathrm{SiO}_{2}\right)$ ve feldispat $\left((\mathrm{Na}, \mathrm{K}) \mathrm{AlSi}_{3} \mathrm{O}_{8} / \mathrm{CaAl}_{2} \mathrm{Si}_{2} \mathrm{O}_{8}\right)$ fazlar1 temel mineralojik kompozisyonu oluşturmaktadır. Gerçekleştirilen kimyasal ve mineralojik analizler literatür verileri ile birlikte ele alındığında, numunenin ara tip $(\mathrm{Na}-\mathrm{Ca})$ bir bentonit olduğu söylenebilir (Çinku, 2008; Zhirong, Azhar Uddin, \& Zhanxue, 2011).

Bentonit numunesinin iki farklı büyütme oranı için SEM görüntüleri Şekil 2'de gösterilmektedir. Şekil 2-(a)'da görüldüğü gibi, numune çoğunlukla 5-10 $\mu \mathrm{m}$ boyutlu tabakalı tanelerden oluşmaktadır. Bu tabakalı yapıyı oluşturan yassı, düzensiz şekilli ve yumrulu nano boyutlu parçacıklar da Şekil 2-(b)'de görülmektedir (Huang et al., 2016).

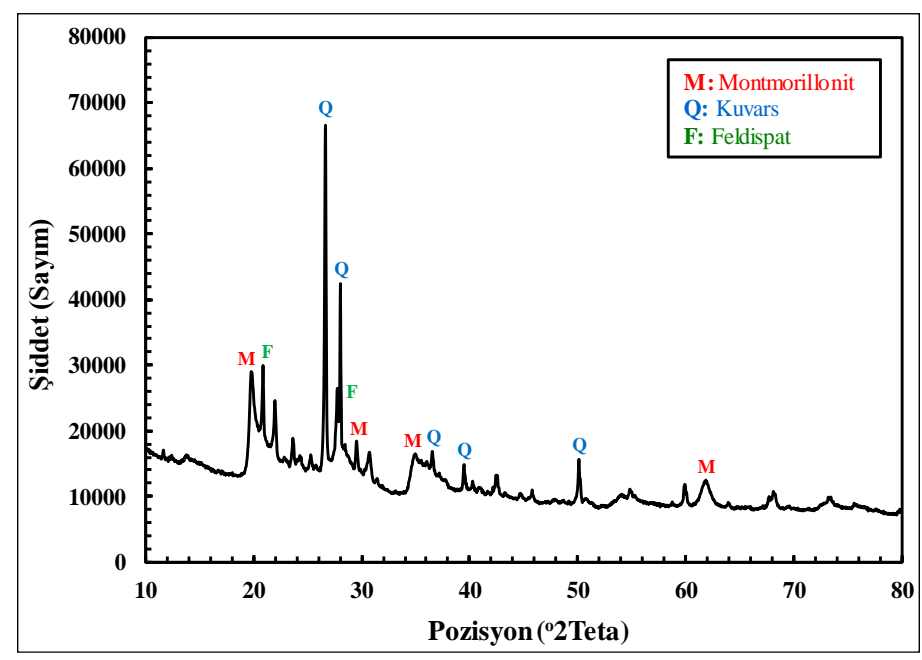

Şekil 1. Bentonit Numunesinin Mineralojik İçeriği 

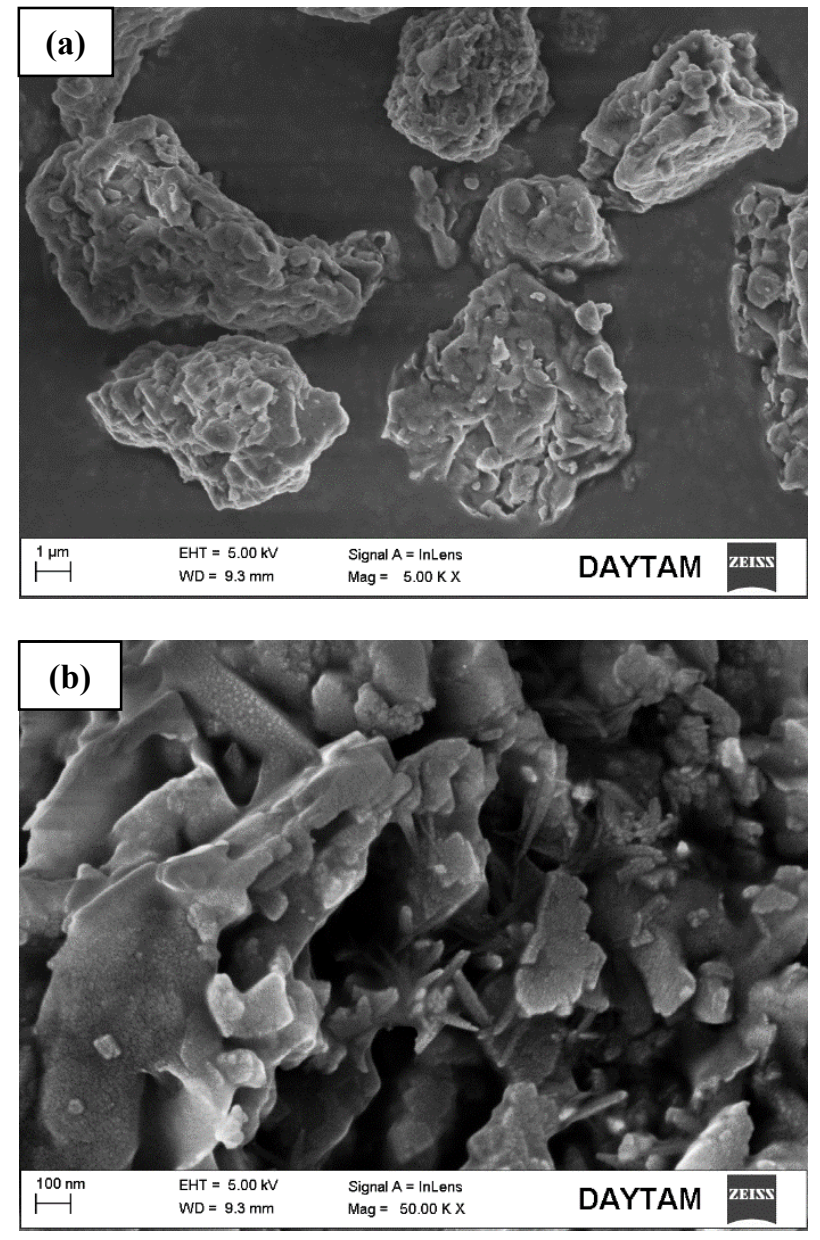

Şekil 2. Bentonit Numunesinin Morfolojik Yapısı

\subsection{Katkısız Çamur Testleri}

Ağırlıkça dört farklı bentonit yüzdesine sahip katkısız çamurların reolojik ve filtrasyon özellikleri, ilgili API standart değerler ile birlikte Tablo 2'de detaylı olarak gösterilmektedir. Elde edilen görünür viskozite değerlerini kullanarak oluşturulan eğriden, $15 \mathrm{cp}$ değerine karşılık gelen ağırlıkça bentonit içeriği $\% 5,35$ olarak belirlenmiş ve buradan çamur verimi $17,69 \mathrm{~m}^{3} /$ ton olarak hesaplanmıştır. API Standardı 13A'ya göre belirlenen alt limit değer $15,8 \mathrm{~m}^{3} /$ ton olduğundan, bentonit numunesinin çamur verimi açısından yeterli olduğu söylenebilir. Görünür viskozite için belirtilen alt sınır olan $15 \mathrm{cp}$, çamur verimi ile uyumlu olarak $\%$ ve üzeri bentonit içerikleri için karşılanmıştır. Akma noktasının plastik viskoziteye oranı sondaj kalite bentonit için yalnızca \%4 katı için sağlanırken, OCMA kalite için ise $\% 4$ ve 6 bentonit içerikleri limit değeri aşmayan sonuçlar sergilemiştir. Su kaybı değerleri OCMA kalite bentonit için, test edilen tüm katı içeriklerinde belirtilen sınır içerisinde kalırken, sondaj kalite için ise yalnızca \%4'lük çamur, limit değeri aşmıştır. Ek olarak, bentonit numunesinin ağırlıkça $\% 2,5$ 'luk $75 \mu \mathrm{m}$ elek üstü boyutu, her iki kalite standardını da karşılamıştır (API, 2010).

Tablo 2. Katkısız Çamur Özellikleri ve API Sınır Değerleri

\begin{tabular}{|c|c|c|c|c|c|c|}
\hline \multirow{2}{*}{ Parametre } & \multicolumn{4}{|c|}{ Bentonit (\% Ağırlık) } & \multicolumn{2}{|c|}{ API Standardı 13A (API, 2010) } \\
\hline & 4 & 6 & 8 & 10 & Sondaj Kalite & OCMA Kalite \\
\hline Görünür Viskozite (cp) & 7 & $\underline{20}$ & $\underline{37}$ & $\underline{65}$ & \multicolumn{2}{|c|}{ En az 15} \\
\hline Plastik Viskozite (cp) & 4 & 5 & 7 & 10 & - & - \\
\hline Akma Noktası $\left(l b f / 100 \mathrm{ft}^{2}\right)$ & 5 & 30 & 63 & 110 & - & - \\
\hline Akma Noktasl/Plastik Viskozite & $\underline{1,25}$ & $\underline{6}$ & 9 & 11 & En çok 3 & En çok 6 \\
\hline Su Kaybı $(m L)$ & $\underline{15,63}$ & $\underline{10,84}$ & $\underline{9,63}$ & $\underline{8,44}$ & En çok 15 & En çok 16 \\
\hline $75 \mu \mathrm{m}$ Yaş Elek Üstü (\% Ă̆ırlık) & \multicolumn{4}{|c|}{$\underline{2,5}$} & En çok 4 & En çok 2,5 \\
\hline Çamur Verimi ( $m^{3} /$ ton $)$ & \multicolumn{4}{|c|}{$\overline{17,69}$} & \multicolumn{2}{|c|}{ En az 15,8} \\
\hline
\end{tabular}

Katkısız çamurlar için elde edilen genel sonuçlar, kullanılan numunenin ilgili API standardına göre \%6 katı içeriği için OCMA kalite bir bentonitte aranan tüm spesifikasyonları sağladığını göstermiştir. Bununla birlikte, plastik viskozite alt limiti için bazı kaynaklarda verilen 7 ve $10 \mathrm{cp}$ değerleri, \%6 bentonit içeriği için karşılanamamaktadır (Çinku, 2008; Özkan \& Kaplan, 2019). Diğer bir deyişle, numunenin pratikte polimer katkısız olarak kullanımının zor olduğu söylenebilir.

\subsection{Polimer Katkılı Çamur Testleri}

Bu bölümde, \%4 ve 6 bentonit içerikleri için QTG ve PV'nin reolojik özellikler, çamur verimi ve su kaybı üzerine etkisi 0,5-3,0 $\mathrm{kg}$ polimer $/ \mathrm{m}^{3}$ çamur aralığında incelenmiş ve API 13-A sondaj kalitesindeki bentonit değerleri referans alınarak yorumlanmıştır. Tablo 3 ve Tablo 4 sirasıyla \%4 ve 6 bentonit içeriği için elde edilen sonuçları sergilemektedir. 
Tablo 3. \%4 Bentonit İ̧eriğinde Polimer Katkllı Çamur Özellikleri

\begin{tabular}{|c|c|c|c|c|c|c|c|c|c|c|c|c|}
\hline \multirow{2}{*}{ Parametre } & \multicolumn{6}{|c|}{ QTG Dozajı $\left(\mathbf{k g} / \mathbf{m}^{3}\right)$} & \multicolumn{6}{|c|}{ PV Dozajı $\left(\mathrm{kg} / \mathrm{m}^{3}\right)$} \\
\hline & 0,5 & 1,0 & 1,5 & 2,0 & 2,5 & 3,0 & 0,5 & 1,0 & 1,5 & 2,0 & 2,5 & 3,0 \\
\hline Görünür Viskozite (cp) & 10,5 & 14 & $\underline{17}$ & $\underline{22}$ & $\underline{23,5}$ & 28 & 14 & $\underline{18}$ & $\underline{27}$ & $\underline{30}$ & $\underline{31}$ & $\underline{32}$ \\
\hline Plastik Viskozite (cp) & $\underline{10}$ & $\underline{10}$ & $\underline{11}$ & $\underline{15}$ & $\underline{17}$ & $\underline{17}$ & 8 & 8 & $\underline{11}$ & $\underline{13}$ & $\underline{14}$ & $\underline{16}$ \\
\hline Akma Noktası (lbf/100 ft $\left.{ }^{2}\right)$ & 1 & $\underline{8}$ & $\underline{12}$ & 14 & $\underline{16}$ & 23 & 12 & $\underline{18}$ & $\underline{28}$ & $\underline{32}$ & $\underline{30}$ & $\underline{30}$ \\
\hline$\tau_{y} / \mu_{p}$ & $\underline{0,1}$ & $\underline{0,8}$ & $\underline{1,09}$ & $\underline{0,93}$ & $\underline{0,94}$ & $\underline{1,35}$ & $\underline{1,5}$ & $\underline{2,25}$ & $\underline{\mathbf{2 , 5 5}}$ & $\underline{2,46}$ & $\underline{2,14}$ & $\underline{1,88}$ \\
\hline Su Kaybı $(m L)$ & $\underline{11,04}$ & $\underline{10,53}$ & 9,80 & $\underline{9,64}$ & $\underline{9,60}$ & $\underline{9,20}$ & $\underline{13,54}$ & $\underline{11,51}$ & $\underline{10,50}$ & $\underline{10,39}$ & $\underline{10,21}$ & $\underline{9,21}$ \\
\hline
\end{tabular}

Tablo 3'den görüldüğü gibi, \%4 bentonit içeriğinde, QTG 1,5 $\mathrm{kg} / \mathrm{m}^{3}$ ve üzerindeki dozajlar için yeterli bir görünür viskozite sağlarken, bu değer PV için $1 \mathrm{~kg} / \mathrm{m}^{3}$ ' dür. Akma noktasının plastik viskoziteye oranı ve su kaybı değerleri, her iki polimerin de test edilen tüm dozajları için karşılanmıştır. Ayrıca plastik viskozite ve akma noktası için istenilen sırasıyla en az $10 \mathrm{cp}$ ve en çok 50 lbf/100 ft ${ }^{2}$ sınır değerlerinin de sağlanması gerekmektedir (Çinku, 2008; Özkan \& Kaplan, 2019). Bu nedenle, tüm sınır değerlerin karşılandığı minimum polimer dozajı her ikisi için de $1,5 \mathrm{~kg} / \mathrm{m}^{3}$ olarak belirlenmiştir.

Tablo 4. \%6 Bentonit İçeriğinde Polimer Katkılı Çamur Özellikleri

\begin{tabular}{|c|c|c|c|c|c|c|c|c|c|c|c|c|}
\hline \multirow{2}{*}{ Parametre } & \multicolumn{6}{|c|}{ QTG Dozajı $\left(\mathrm{kg} / \mathrm{m}^{3}\right)$} & \multicolumn{6}{|c|}{ PV Dozajı $\left(\mathrm{kg} / \mathrm{m}^{3}\right)$} \\
\hline & 0,5 & 1,0 & 1,5 & 2,0 & 2,5 & 3,0 & 0,5 & 1,0 & 1,5 & 2,0 & 2,5 & $\mathbf{3 , 0}$ \\
\hline Görünür Viskozite (cp) & $\underline{19}$ & $\underline{21,5}$ & $\underline{27}$ & $\underline{30}$ & $\underline{37,5}$ & $\underline{38}$ & $\underline{34,5}$ & $\underline{40,5}$ & $\underline{43,5}$ & $\underline{47}$ & $\underline{48}$ & $\underline{47}$ \\
\hline Plastik Viskozite (cp) & 9 & $\underline{11}$ & 14 & 14 & 20 & 23 & 9 & 10 & 11 & 12 & $\underline{16}$ & 22 \\
\hline Akma Noktası (lbf/100 ft $\left.{ }^{2}\right)$ & $\underline{20}$ & $\underline{21}$ & $\underline{26}$ & $\underline{32}$ & $\underline{35}$ & $\underline{35}$ & 51 & 63 & 66 & 66 & 64 & 60 \\
\hline$\overline{\tau_{y} / \mu_{p}}$ & $\underline{2,22}$ & $\underline{1,91}$ & $\underline{1,86}$ & $\underline{2,29}$ & $\underline{1,75}$ & $\underline{1,52}$ & 5,67 & 6,3 & 6 & 5,5 & 4 & $\underline{2,73}$ \\
\hline Su Kaybı $(m L)$ & $\underline{8,65}$ & $\underline{7,94}$ & $\underline{7,80}$ & $\underline{7,71}$ & $\underline{7,63}$ & $\underline{7,55}$ & $\underline{9,80}$ & $\underline{8,84}$ & $\underline{8,30}$ & $\underline{8,28}$ & $\underline{8,04}$ & $\underline{8,0}$ \\
\hline
\end{tabular}

Tablo 4'den görüldüğü gibi, \%6 bentonit içeriğinde her iki polimer için de, görünür viskozite değerleri test edilen tüm dozajlar için karşılanırken, yeterli plastik viskozite değerlerine 1 $\mathrm{kg} / \mathrm{m}^{3}$ ve üzerindeki dozajlarda ulaşılmıştır. Akma noktası tüm QTG dozajları için istenilen sınır içerisinde kalırken, PV oldukça yüksek akma noktası değerlerine neden olmuştur. Benzer şekilde, akma noktasının plastik viskoziteye oranı tüm QTG dozajları tarafından karşılanırken, PV ise yalnızca $3 \mathrm{~kg} / \mathrm{m}^{3}$ için uygun bir değer sağlamıştır. Filtrasyon özelliği açısından her iki polimer de standarda uymaktadır. Tablo 4 genel olarak, $\% 6$ bentonit içeriğinde $1 \mathrm{~kg} / \mathrm{m}^{3}$ QTG dozajının tüm sınır değerleri karşıladığını, PV'nin ise bu katı içeriğinde kullanılmasının mümkün olmadığını göstermektedir.

Tablo 5. Polimer Katkılarının Çamur Verimine Etkisi

\begin{tabular}{l|c|c|c|c|c|c|c|c|c|c|c|c}
\hline \multirow{2}{*}{ Parametre } & \multicolumn{4}{|c|}{ QTG Dozajı $\left(\mathbf{k g} / \mathbf{m}^{\mathbf{3}}\right)$} & \multicolumn{4}{c}{ PV Dozajı $\left(\mathbf{k g} / \mathbf{m}^{\mathbf{3}}\right)$} \\
\cline { 2 - 12 } & $\mathbf{0 , 5}$ & $\mathbf{1 , 0}$ & $\mathbf{1 , 5}$ & $\mathbf{2 , 0}$ & $\mathbf{2 , 5}$ & $\mathbf{3 , 0}$ & $\mathbf{0 , 5}$ & $\mathbf{1 , 0}$ & $\mathbf{1 , 5}$ & $\mathbf{2 , 0}$ & $\mathbf{2 , 5}$ & $\mathbf{3 , 0}$ \\
\hline Çamur Verimi $\left(\mathrm{m}^{3} /\right.$ ton $)$ & 18,61 & 22,26 & 27,58 & $\underline{36,04}$ & 37,47 & 41,67 & 23,40 & 27,55 & 44,47 & $\underline{49,01}$ & 51,70 & 51,70 \\
\hline
\end{tabular}

QTG ve PV polimer katkılarının çamur verimine etkisi Tablo 5 'de gösterilmektedir. Tablo 5'de görüldüğü gibi, çamur verimi açısından her iki polimer de $2 \mathrm{~kg} / \mathrm{m}^{3}$ dozajda optimum değerler sağlamıştır. Daha yüksek dozajlar için ise kayda değer bir artış meydana gelmemiştir. Tablo 3-5 birlikte ele alındığında, QTG'nin su kaybı kontrolü, PV'nin ise daha çok kıvamlaştırma amacıyla kullanımının uygun olduğu söylenebilir.

\section{Sonuç}

Ağırlıkça \%4, 6, 8 ve 10 bentonit kullanarak gerçekleştirilen katkısız çamur testleri, numunenin API standardı 13-A'ya göre \%6 katı içeriğinde OCMA kalite bir bentonitte aranan tüm spesifikasyonları sağladığını göstermiştir. Ancak bu katı içeriği için elde edilen düşük plastik viskozite $(5 \mathrm{cp})$ ve yüksek akma noktasının plastik viskoziteye oranı (6) değerleri, bentonit numunesinin sondajda direkt olarak kullanımının mümkün olmadığını göstermiştir. Bu nedenle, $\% 4$ ve 6 bentonit içerikleri için farklı yapıdaki iki polimerin çamur özelliklerine etkisi 0,5 $3,0 \mathrm{~kg} / \mathrm{m}^{3}$ dozaj aralığında incelenmiştir. \%4 bentonit içeriğinde, QTG ve PV polimerlerinin her ikisi de $1,5 \mathrm{~kg} / \mathrm{m}^{3}$ dozaj değerinde API 13-A sondaj kalite bentonit için aranan tüm sınır değerleri karşılamıştır. \%6 bentonit içeriğinde ise test edilen tüm çamur spesifikasyonları $1 \mathrm{~kg} / \mathrm{m}^{3}$ QTG için karşılanmıştır. Bununla beraber, elde edilen yüksek akma noktası ve akma noktasının plastik viskoziteye oranı değerleri, PV'nin bu katı içeriğinde kullanımının güç olduğunu göstermiştir. Genel sonuçlar, QTG ve PV'nin sırasıyla filtrasyon ve reolojik özellikler üzerine etkinliğini ortaya koymuştur. Sonuç olarak, ağırlıç̧a \%4 bentonit numunesi içeren çamurlar, QTG ve PV polimerlerinin $1,5 \mathrm{~kg} / \mathrm{m}^{3}$ dozajı için sondaj kalite standardını sağlamıştır. Çok düşük su 
kaybı istenilen durumda QTG, yüksek viskozite ve çamur verimi istenilen durumda ise PV'nin seçimi uygun olacaktır.

\section{Teșekkür}

$\mathrm{Bu}$ çalışmada, Atatürk Üniversitesi Bilimsel Araştırma Projeleri Koordinasyon Birimi FLP-2019-7994 nolu Lisans Öğrencisi Katılımlı Araştırma Projesinden elde edilen sonuçlar kullanılmıştır. Deneylerde kullanılan bentonit numunesinin tedarik edilmesini sağlayan Maden Mühendisi Tansel Akyüz özelinde Çanbensan A.Ş.'ye, polimer katkılarını temin eden Kayen Sondaj firmasına ve projenin gerçekleştirilmesi için maddi destek sağlayan Atatürk Üniversitesi Toplumsal Duyarlılık Projeleri Uygulama ve Araştırma Merkezi'ne teşekkürlerimizi sunariz.

\section{Kaynakça}

API. (2010). American Petroleum Institute (API) Specification 13A (9-11). In Specification for Drilling Fluids. USA.

Asker, N., Özkan, V., \& Özkan, A. (2019). Su Bazlı Sondaj Çamurunun Reolojik ve Filtrasyon Özelliklerine $\mathrm{ZnO}$ Nanopartikülü ile Fonksiyonelleştirilmiş Çok Duvarlı Karbon Nanotüpün Etkisinin Araştırllması. Paper presented at the Euro Asia 5th. International Congress on Applied Sciences, Adana, Turkey.

Avc1, E. (2018). Jeotermal Sularla Hazırlanmış Çamurların Sondaj Performansina Etkisi. (Yüksek Lisans Tezi). İskenderun Teknik Üniversitesi, Hatay. Retrieved from http://openaccess.iste.edu.tr/xmlui/bitstream/handle/20.500. 12508/413/emineavc $\% \mathrm{C} 4 \% \mathrm{~B} 1 . \mathrm{pdf}$ ? sequence $=1 \&$ is Allowed $=\mathrm{y}$

Balkaya, A. T., Gül, S., İlgen, E., Dimez, A. B., Deniz, S., Heke, E., . . E Erşahin, A. (2019). Sondaj El Kitabı. Ankara: Petrol Mühendisleri Odası Yayınları.

Çinku, K. (2008). Aktivasyon Yöntemleri ile Bentonitten Su Bazlı Kıvamlaştırıcı Üretiminin Araştırllması. (Doktora Tezi). İstanbul Üniversitesi, İstanbul. Retrieved from http://nek.istanbul.edu.tr:4444/ekos/TEZ/43360.pdf
Erdoğan, Y., Kök, O. E., \& Tanrıverdi, İ. (2017). Çanakkale Tuzla Jeotermal Sondaj Sahası Çamur Maliyetinin Araştırılması. Çukurova University Journal of the Faculty of Engineering and Architecture, 32(4), 11-20. Retrieved from https://muhendislik.cu.edu.tr/tr/Dergi/(32 4 2017)/02.pdf

Huang, W., Leong, Y.-K., Chen, T., Au, P.-I., Liu, X., \& Qiu, Z. (2016). Surface chemistry and rheological properties of API bentonite drilling fluid: $\mathrm{pH}$ effect, yield stress, zeta potential and ageing behaviour. Journal of Petroleum Science and Engineering, 146, 561-569. doi:https://doi.org/10.1016/j.petrol.2016.07.016

Karg1, E. (2015). Sondaj Çamuru Uygulamaları İçin Kil-Polimer Etkileşimlerinin Belirlenmesi. (Yüksek Lisans Tezi). İstanbul Teknik Üniversitesi, İstanbul. Retrieved from http://hdl.handle.net/11527/13352

Okon, A. N., Udoh, F. D., \& Bassey, P. G. (2014). Evaluation of Rice Husk as Fluid Loss Control Additive in Water-Based Drilling Mud. Paper presented at the SPE Nigeria Annual International Conference and Exhibition, Lagos, Nigeria. https://www.onepetro.org/conference-paper/SPE-172379. MS

Onat, N. (1971). Bentonitin Petrol Sondajlarında Kullanılması. Bilimsel Madencilik Dergisi, 10(5), 30-36. Retrieved from http://www.maden.org.tr/resimler/ekler/634.pdf

Özkan, A., \& Kaplan, B. M. (2019). Investigation of the Effects on Rheological and Filtration Properties of Water-Based Drilling Mud of Boron Minerals: An Experimental Study. Pamukkale University Journal of Engineering Sciences, 25(7), 884-888. doi:10.5505/pajes.2019.89990

Yenipazar, Y. (2000). Büyükkılıçlı (Silivri) Bentonitinin Döküm ve Sondaj Sanayi Yönünden Özelliklerinin Incelenmesi. (Yüksek Lisans Tezi). İstanbul Teknik Üniversitesi, İstanbul. Retrieved from http://hdl.handle.net/11527/11256

Zhirong, L., Azhar Uddin, M., \& Zhanxue, S. (2011). FT-IR and XRD analysis of natural Na-bentonite and $\mathrm{Cu}(\mathrm{II})$-loaded Nabentonite. Spectrochimica Acta Part A: Molecular and Biomolecular Spectroscopy, 79(5), 1013-1016. doi:https://doi.org/10.1016/j.saa.2011.04.013 